\title{
Modeling Electromagnetic Signal Levels Falling on Aircraft from Satellite Communication Systems
}

\author{
Clifford De Raffaele, Carl J. Debono and Adrian Muscat \\ Department of Communications and Computer Engineering \\ University of Malta, MSD 2080 \\ Malta \\ cderaffaele@iieee.org, c.debono@ieee.org, adrian.muscat@um.edu.mt
}

\begin{abstract}
The persistent growth in demand for broadband communication services has lead to the widespread deployment of high-frequency Ka-Band satellite communication systems. This phenomenon however, presents a scenario whereby aircraft in mid-flight are evermore subjected to a diversity of external high frequency signals. The latter can potentially generate Electromagnetic Interference (EMI) with the communications and control avionic systems onboard the aircraft. These drastic effects are becoming increasingly noteworthy, and the aircraft industry is progressively seeking more thorough electromagnetic compatibility assessments prior to aircraft manufacture. ${ }^{12}$
\end{abstract}

To this end, this paper proposes a novel study that computationally models the electromagnetic effects incident on aircraft fuselage from external high frequency sources. An accurate ray-tracing framework was employed for the assessment of the power incident from a terrestrially based Ka-band antenna onto a small sized aircraft whilst flying. Subsequent to the determination of an illumination cone technique, to increase simulation efficiency and accuracy, a customized 3D ray-tracing technique based on Geometric Optics (GO) was used to simulate the propagation characteristics. This asymptotic area-oriented methodology was able to reliably assess the EM field incident on the entire fuselage structure. In addition, the peculiar characteristics of EM waves at the $30 \mathrm{GHz}$ frequency range demanded the inclusion of atmospheric fade phenomena that imposed significant contributions to the attenuation of the EM field. Thus, the performed simulation accounted for signal losses due to rain, fog, cloud, gaseous and also tropospheric scintillation. A large number of rays impeding via an array of diverse propagation paths and techniques were comprehensively considered and the 3D vectorial summation of the resultant EMI field incident on each location was conclusively executed.

The paper illustrates the developed theoretical model by presenting computed results for an Evektor EV-55 business aircraft under the typical atmospheric conditions of Genève, Switzerland for an availability rate of $99 \%$. This was done because of the extensive atmospheric data available for this location that could be compared with the results obtained from the model. Moreover, the versatility of the developed

\footnotetext{
${ }^{1}$ 978-1-4244-7351-9/11/\$26.00 C2011 IEEE.

${ }^{2}$ IEEEAC paper \#1355, Version 1, Updated November 16, 2010
}

framework lends itself perfectly to the EMI verification of aircraft models, whereby manufacturers can avoid expensive measurement campaigns at the design stage.

\section{TABLE OF CONTENTS}

1. INTRODUCTION .................................................... 1

2. RAY-TRACING FRAMEWORK ..................................... 2

3. PROPAGATION PARAMETERS ...................................... 3

4. SIMULATION AND RESULTS ....................................... 5

5. CONCLUSION .............................................................6 6

ACKNOWLEDGMENT ........................................................... 6

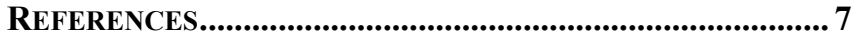

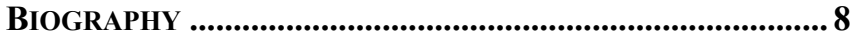

\section{INTRODUCTION}

The advancement registered during the last decade in satellite telecommunications and broadcasting technologies has lead to significant spectral congestion of the conventional frequency bands [1]. This has invoked engineers to focus attention on higher frequencies well above of $10 \mathrm{GHz}(\mathrm{Ku}, \mathrm{Ka}$ and $\mathrm{V}$ bands) for the design of new fixed satellite services. These higher carrier frequency bands offer wider bandwidths, higher data rates and smaller terrestrial component sizes [2] [3].

Simultaneous to this progress, modern aircraft are evermore employing a complex suite of electronic systems for navigation, control and internal communications during flight [4]. This electronic dependence implies that flight safety can only be guaranteed for the unimpeded operation of these systems [5]. The need for prevention of integrity compromisation from electromagnetic interference (EMI) has lately attracted much attention from the aeronautic industry and research community alike [6]. Much effort has been done so far to study and predict the effects induced by onboard personal wireless electronic devices (PEDs) by means of simulation and measurement campaigns [7 - 10]. Manufacturers are also required to test their aircraft models for EM compatibility testing prior to service engagement, as to ensure safety from onboard interference [11] [12].

During flight however, aircrafts are also prone to EM fields emanating from external sources and are subject to penetration of high intensity radiated fields (HIRF) into conducting enclosures via apertures. In a number of occasions it has been proven that EM sources external to the 
aircraft have been responsible for the disruption of communications, disabling of navigation avionics and causing several problems to the equipment of airplanes [13]. Such instances pose critical safety issues to the aerospace industry, demanding the need for EMI prediction tools at aircraft design stage as to ensure EM immunity to paramount avionic systems.

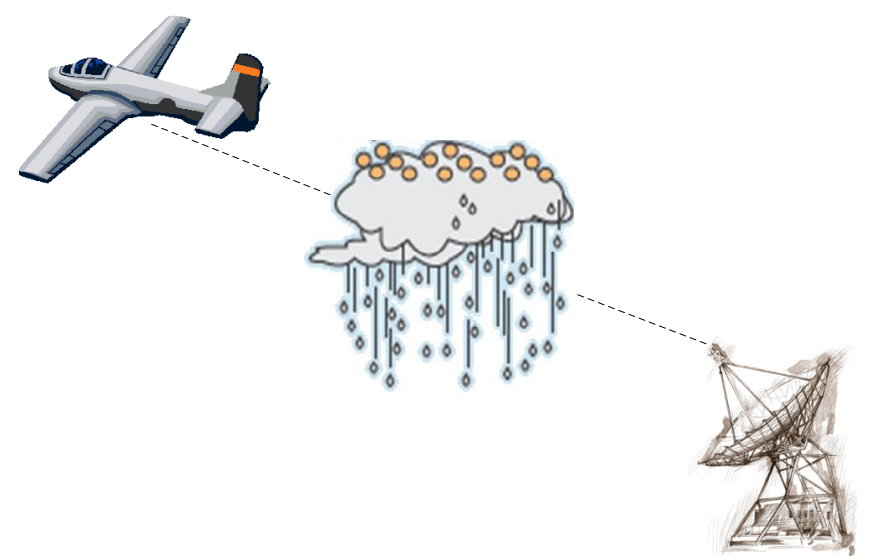

Figure 1: Ray-Tracing simulation to model the EM field incident on the aircraft from external sources with inclusion of atmospheric effects at high-frequencies.

To this end, this paper presents a novel study regarding the effects induced on aircraft from satellite based communication. A terrestrial-based antenna operating at Kaband frequencies is considered and an accurate ray-tracing framework implemented for EMI prediction on the aircraft fuselage as depicted in Figure 1.

\section{RAY-TRACING FRAMEWORK}

Calculation of the EMI field incident on the outer fuselage structure was performed by the implementation of an area oriented design based on ray launching technique, derived from previous developments performed for interior propagation analysis [6]. This approach encompassed a computational complexity which is quasi independent on the number of observation points, and linearly dependent on the number of rays considered [14]. Simulating rays at Kaband frequencies implies that the wavelengths considered are much smaller than the dimensions of the simulated aircraft model. Hence, the Geometric Optics (GO) hypothesis was adopted in the simulation, whereby EM propagation can be modeled as distinct rays and the latter can be executed separately through diverse propagation mechanisms [15].

The model takes into consideration a fixed transmission earth station antenna operating at a defined equivalent isotropic radiated power (EIRP) defined by:

$$
P_{\text {EIRP }}=P_{i n} * h *\left(\frac{\pi D}{\lambda}\right)^{2}
$$

where $P_{\text {in }}$ is the power applied to the input terminals of the antenna, $D$ is the diameter of the satellite dish, $h$ is the net efficiency bounded between $0<h<1$, and $\lambda$ is the wavelength considered.

Simulation efficiency is attained by only considering rays that influence the aircraft from the antenna. This, was achieved by initially establishing an illumination cone from the antenna towards the aircraft by accounting for their respective 3D locations, as exemplified in Figure 2. Subsequent to this process, rays are launched following a Monte-Carlo random method for spherical coordinates bounded by the derived cone dimensions.

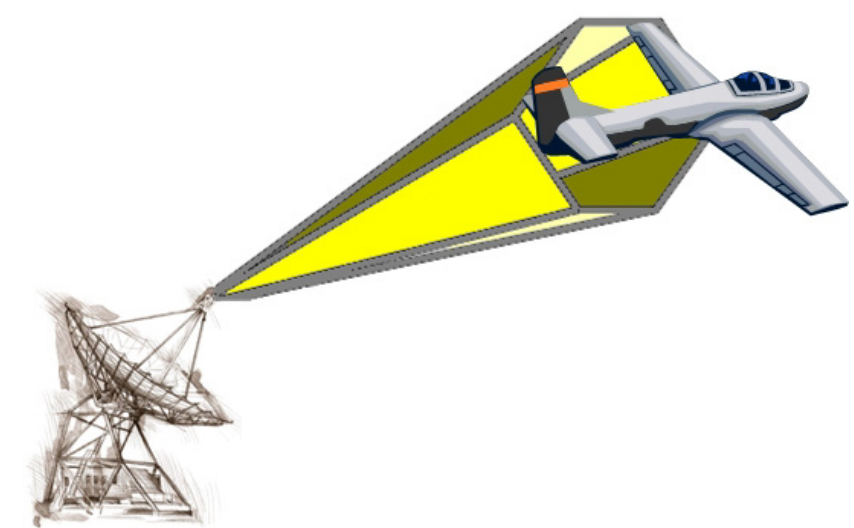

Figure 2: Illumination cone derived between the earth-based antenna and the modeled aircraft for ray launching

The wavefront of the propagating ray is modeled perpendicular to its direction of motion [16]. To account for polarization effects, each ray is separated into parallel and perpendicular components for calculation, denoted by $\|$ and $\perp$ subscripts respectively [17]. The basis of the ray-tracing technique involves the description of the EM field causing interference at any point as the sum of the rays incident on the location after undergoing a number of propagation mechanisms [18]. The attenuation experienced by a ray whilst traveling though free-space was modeled by employing Friis equation whereby the signal will decrease in intensity with the inverse square of distance [19]:

$$
P_{r}=P_{t} G_{r} G_{t}\left(\frac{\lambda}{4 \pi d}\right)^{2}=P_{E I R P}\left(\frac{\lambda}{4 \pi d}\right)^{2}
$$

where $P_{r}$ is the received incident power, $P_{t}$ is the transmitted power from the antenna, $d$ symbolizes the distance traveled by the wavefront, whilst $G_{t}$ and $G_{r}$ represent the transmitter and receiver gain, with the latter being equivalent to one due to the aircraft structure. However, performing analysis for Ka-band propagation implies that the signal attenuation phenomena occurring due to atmospheric losses must be considered [20] as described in further detail in Section 3.

When a ray collides with the modeled aircraft, which represents a boundary consisting of two media with different electromagnetic conductivity and permittivity 
parameters, a simplification of Maxwell's Equations is adopted for the expression of the reflected and transmitted coefficient [21]. This approach employs the use of commonly referred to Fresnel's Equations:

$$
\begin{gathered}
T_{\perp}=\frac{2 \mu_{t} \eta_{i} \cos \theta_{i}}{\mu_{t} \eta_{i} \cos \theta_{i}+\mu_{i} \eta_{t} \cos \theta_{t}} A_{\perp}, \\
R_{\perp}=\frac{\mu_{t} \eta_{i} \cos \theta_{i}-\mu_{i} \eta_{t} \cos \theta_{t}}{\mu_{t} \eta_{i} \cos \theta_{i}+\mu_{i} \eta_{t} \cos \theta_{t}} A_{\perp}, \\
T_{\|}=\frac{2 \mu_{t} \eta_{i} \cos \theta_{i}}{\mu_{i} \eta_{t} \cos \theta_{i}+\mu_{t} \eta_{i} \cos \theta_{t}} A_{\|}, \\
R_{\|}=\frac{-\mu_{i} \eta_{t} \cos \theta_{i}+\mu_{t} \eta_{i} \cos \theta_{t}}{\mu_{i} \eta_{t} \cos \theta_{i}+\mu_{t} \eta_{i} \cos \theta_{t}} A_{\|} .
\end{gathered}
$$

where $\mathrm{A}$ is the parallel or perpendicular component of the power of the incident ray on the boundary, subscripts $i$ and $t$ represent the medium in which incidence and transmission will occur respectively. $\theta$ symbolizes the angle of the ray with the vector normal to the point of intersect, whilst $\eta$ and $\mu$ represent the complex refractive index and permeability of the boundary media respectively. The reflected ray of the fuselage is additionally also inferred a phase shift of $\pi$ so as to accurately account for the multipath interference generated by the same ray [22].

The directions by which the reflected and transmitted rays propagate are derived by employing the mathematics of three-dimensional vectors in [23]:

$$
\begin{gathered}
R=2(N \cdot I) N-I \\
T=\left(\frac{\eta_{i}}{\eta_{t}} N \cdot I-\sqrt{1-\frac{\eta_{i}^{2}}{\eta_{t}^{2}}\left[1-(N \cdot I)^{2}\right]}\right) N-\frac{\eta_{i}}{\eta_{t}} I
\end{gathered}
$$

where $I$ represents vector incident on the boundary, $N$ is the $3 \mathrm{D}$ normal vector to the plane and $(\cdot)$ refers to the dot product operation between vectors. Rays are modeled in the simulator until the signal strength of each component falls below $-150 \mathrm{dBm}$, at which point the contribution of the former to the vectorial addition of the total EMI losses significance [24].

\section{Propagation Parameters}

The propagation effects experienced in earth-space communication mainly originate in the troposphere and ionosphere regions of the atmosphere. Ionospheric effects are of major concern for systems operating below the $3 \mathrm{GHz}$ range, whilst tropospheric phenomena influence significantly systems operating above the $3 \mathrm{GHz}$ frequencies [25].
Aircraft in flight travel through the troposphere at an altitude of 11,000 meters, thus implying that the attenuation phenomena experienced by rays originating from earth stations through the troposphere had to be accounted for. A number of complex meteorological mechanisms contribute to the overall EM attenuation experienced by the transmitted signal. Nevertheless, for frequencies below $100 \mathrm{GHz}$, the most influencing phenomena are considered to be rain precipitation, atmospheric gaseous absorption, clouds, fog and tropospherical scintillation [26].

\section{Rain Attenuation}

Attenuation due to rain is the dominant propagation impairment for Ka-band communications. This attenuation in dependent on a number of parameters, namely; the operating frequency, antenna elevation angle, polarization of the transmitted signal, ground station height above sea level, and the rainfall rate calculated for a specific coordinate on the globe. The latter value is also dependent on rain availability that is considered, which infers on the percentage of time that the available rain margin is not exceeded [27]. The implemented model is based on the ITU-R P.618 recommendation [28] and simulation results were verified by comparing to the respective ITU-R reference validation documents.

During analysis, it was noticed that the signal polarization can have significant effects on the rain attenuation experienced. This is due to the vertically elongated shape of most raindrops, which lead to horizontal polarized signals being more heavily attenuated than their vertical counterparts [29]. This variance is nonetheless counteracted by the implementation of circular polarization which attains a consistent attenuation pattern through rain.

Figure 3 illustrates the attenuation achieved at Genève, Switzerland for an availability rate of $99 \%$ and circular polarization for different elevation angles.

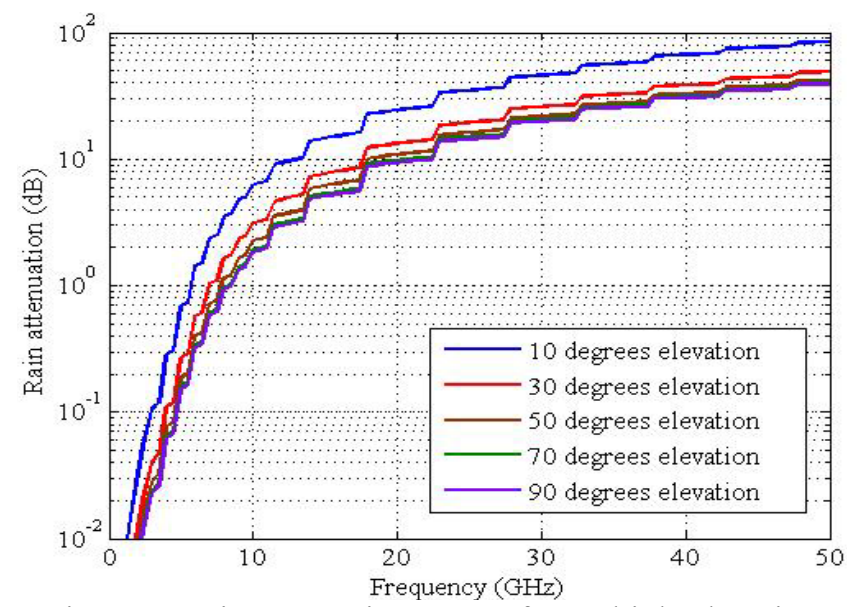

Figure 3: Rain attenuation curves for multiple elevation angles through a range of frequencies. 


\section{Gaseous Absorption}

Absorption occurring due to atmospheric gases is less influential than that due to rain. This phenomenon is dependent mainly on elevation angle, atmospheric water vapor at specific global coordinates and frequency of operation. The main contributors to gaseous attenuation are water vapor and oxygen with the former exhibiting a behavior dependent on air temperature, pressure and absolute humidity, whilst the oxygen attenuation is invariant to climatic conditions [30].

Modeling of the gaseous phenomenon was performed by implementation of ITU-R P.676 recommendation [31], which approximates a line-by-line stratified atmospheric layers calculation to a computationally tractable result. This implementation considers the attenuation generated from the main constituents separately as a function of frequency as demonstrated by Figure 4:

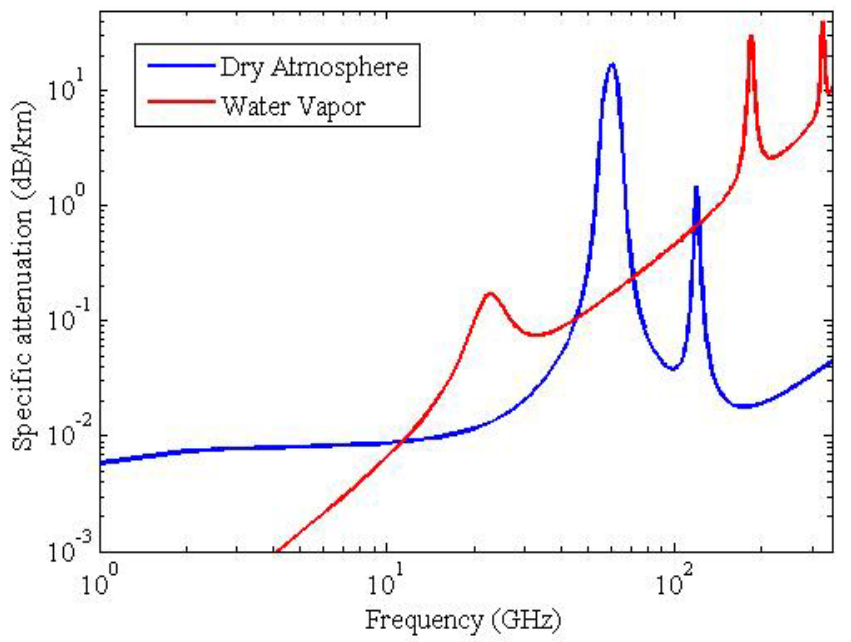

Figure 4: Specific attenuation against frequency for water vapor at a mean of $7.5 \mathrm{gr} / \mathrm{m}^{3}$ and for dry atmosphere.

These oxygen and water vapor component values, denoted respectively by $\gamma_{0}$ and $\gamma_{\mathrm{w}}$, are subsequently employed for the derivation of the attenuation due to gaseous absorption for a slant path by the equation [31]:

$$
A=\frac{h_{0} \gamma_{0}+h_{w} \gamma_{w}}{\sin \theta}(d B)
$$

where $\theta$ is the elevation angle and the variables $h_{o}$ and $h_{w}$ represent the equivalent height of dry air and water vapour respectively as expressed by the equations:

$$
\begin{aligned}
& h_{0}=5.386-3.32734 \times 10^{-2} f+1.87185 \times 10^{-3} f^{2} \ldots \\
& -3.52087 \times 10^{-5} f^{3}+\frac{83.26}{(f-60)^{2}+1.2}(\mathrm{~km})
\end{aligned}
$$

$$
h_{w}=1.65\left(\begin{array}{l}
1+\frac{1.61}{(f-22.23)^{2}+2.91}+\frac{3.33}{(f-183.3)^{2}+4.58} \ldots . . \\
+\frac{1.90}{(f-325.1)^{2}+3.34}
\end{array}\right)(\mathrm{km})
$$

\section{Cloud/Fog Attenuation}

Clouds are composed of both water droplets and ice. The influence of ice clouds is negligible to that contributed by water droplets. The latter is based on a mathematical model of Rayleigh scattering employing the double-Debye model for dielectric complex permittivity of water as in recommendation ITU-R P.840 [32]. The attenuation exhibited by this phenomenon is calculated by:

$$
A=\frac{L K_{l}}{\sin \theta}(d B)
$$

where $L$ is the columnar content of liquid water deduced from recommendation ITU-R P.836 [33] for the specific location on the globe, $\theta$ is the elevation angle and the specific attenuation coefficient $K_{l}$ is mathematically computed as a function of temperature, primary and secondary relaxation frequencies. Figure 5 illustrates the values attained for this constant over a range of frequencies for different temperature coefficients.

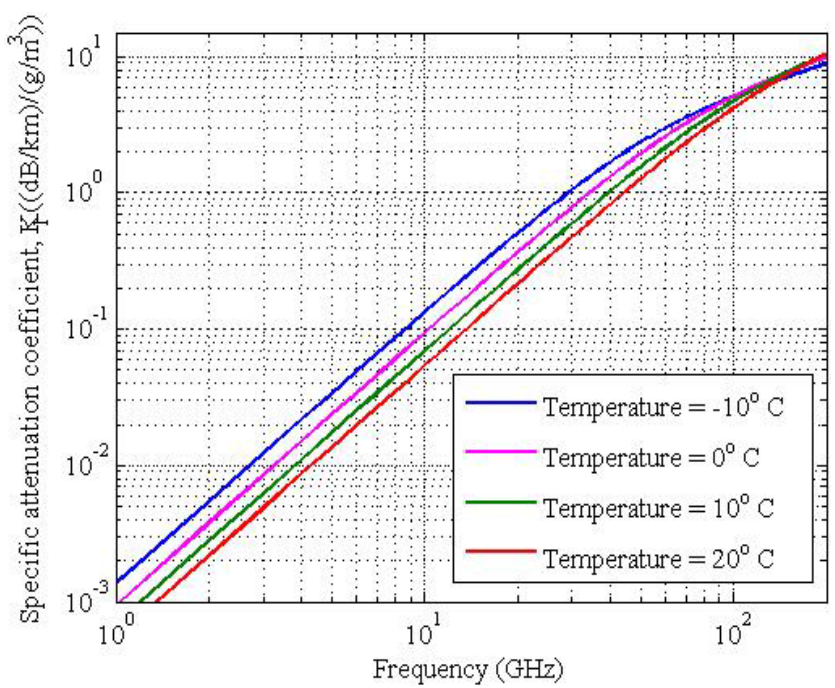

Figure 5: Specific cloud attenuation coefficient for multiple temperatures through a range of frequencies.

\section{Tropospheric Scintillation}

Scintillations are the fast fluctuations of signal amplitude and phase that are resultant from atmospheric turbulence. This effect occurs from turbulent irregularities in temperature, humidity and pressure, which translate into small-scale variations in the refractive index of the troposphere region [34]. The attenuation due to tropospheric scintillation becomes influential as the frequencies are increased over $10 \mathrm{GHz}$ and at elevation angles of less than 15 degrees. The implementation of this attenuation 
phenomenon was performed according to the accurate technique derived by Van der Kamp [35][36].

Figure 6 illustrates the attenuation occurring due to Tropospheric Scintillation at Genève, Switzerland for an availability rate of $99 \%$ and a temperature of $6^{\circ} \mathrm{C}$ for different elevation angles.

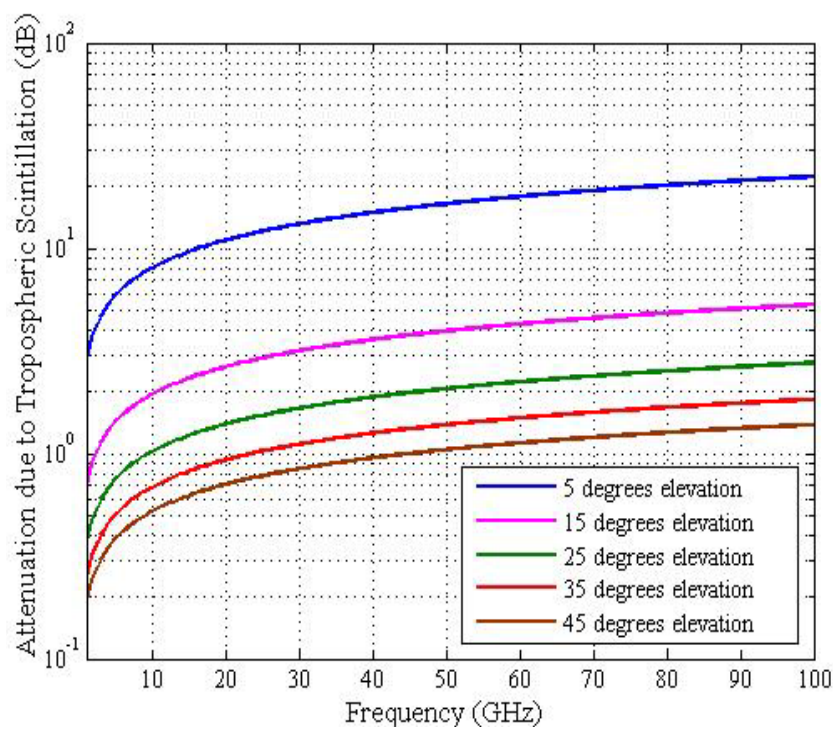

Figure 6: Tropospheric Scintillation attenuation curves for multiple elevation angles through a range of frequencies.

\section{Total Tropospheric Attenuation}

The significant attenuation parameters modeled individually exhibit a complex interaction between them, which must be accounted for in calculation. This is mainly due to the correlation of the simultaneous multiple sources in the atmosphere, particularly for frequencies above $18 \mathrm{GHz}$. The total attenuation for a fixed availability can hence be expressed as [28]:

$$
A_{T}=A_{G}+\sqrt{\left(A_{R}+A_{C}\right)^{2}+A_{s}^{2}}(d B)
$$

where $A_{R}$ represent the attenuation due to rain, $A_{C}$ and $A_{S}$ are the contributions due clouds and scintillation respectively, and $A_{G}$ is the combination of water vapor and oxygen attenuations.

\section{Simulation And Results}

The algorithm developed in this paper was used to model the EMI field incident from a Ka-band earth station onto the fuselage of a small business aircraft. The latter was represented by replicating the geometry of the Evektor EV55 Outback passenger aircraft [37] with a spatial resolution of $2 \mathrm{~cm}$ along 3D directions on the Maltab ${ }^{\circledR}$ platform.

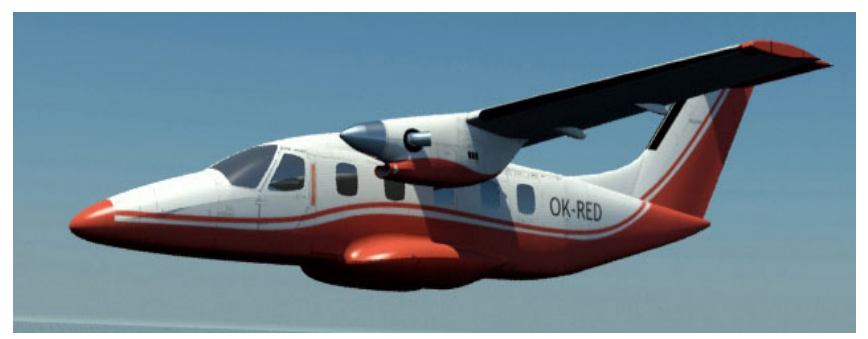

Figure 7: Evektor EV-55 business jet [37], as included in the electromagnetic propagation simulation.

As represented in Figure 7, the external geometry of the aircraft was composed mainly from an aluminum fuselage furnished with acrylic windowpanes, having the electromagnetic parameters defined in Table 1.

TABLE I

Electromagnetic Material Properties

\begin{tabular}{|l|c|c|c|}
\hline \multirow{2}{*}{ Parameters } & \multicolumn{3}{|c|}{ Material } \\
\cline { 2 - 4 } & Air & Aluminum & Acrylic \\
\hline Permittivity $(\varepsilon)$ & 1.0006 & 1.0005 & 3.4 \\
\hline Permeability $(\mu)$ & 1 & 1.000022 & 1 \\
\hline $\begin{array}{l}\text { Electrical } \\
\text { Conductivity }(\sigma)\end{array}$ & $5 \mathrm{e}^{-15}$ & $4 \mathrm{e}^{7}$ & $1 \mathrm{e}^{-12}$ \\
\hline
\end{tabular}

An earth station antenna transmitting with a nominal power of $1 \mathrm{~W}$ from a satellite dish diameter of $1 \mathrm{~m}$ at a conservative estimate efficiency of 0.5 [28] was simulated. This simulation was based at the geographical coordinates (46.217, 6.12) in Genève, Switzerland for an availability rate of $99 \%$. This presented an equivalent isotropic radiated power, $\mathrm{P}_{\text {EIRP, }}$ of $76.94 \mathrm{dBm}$ which was the initial value assigned to the rays for propagation.

An asymptotic calculation of the EMI incident on the aircraft was achieved by launching 200,000 unique rays from the antenna within the illumination cone described in Section 2. Depending on the impinged surface, the incident ray can either be completely reflected or partially absorbed by means of a transmitted ray into the boundary medium. The former case occurs when the ray interacts with an aluminum surface, since the material presents a very high electrical conductivity in the $30 \mathrm{GHz}$ frequency range. Transmitted rays arise when the incident ray impinges on the fuselage apertures, which are represented by windowpane material. Subsequent to the primary interaction with the boundary, the simulator computes the EM propagation by the reflected ray until the latter is either incident on a second boundary medium or results in an EM field strength which is less than $-150 \mathrm{dBm}$. The global EM field is finally determined by performing a vectorial summation of the power levels from all multipath components that intersected the fuselage locations. For the described simulation, the results attained on the Evektor EV-55 aircraft are illustrated in Figure 8. 


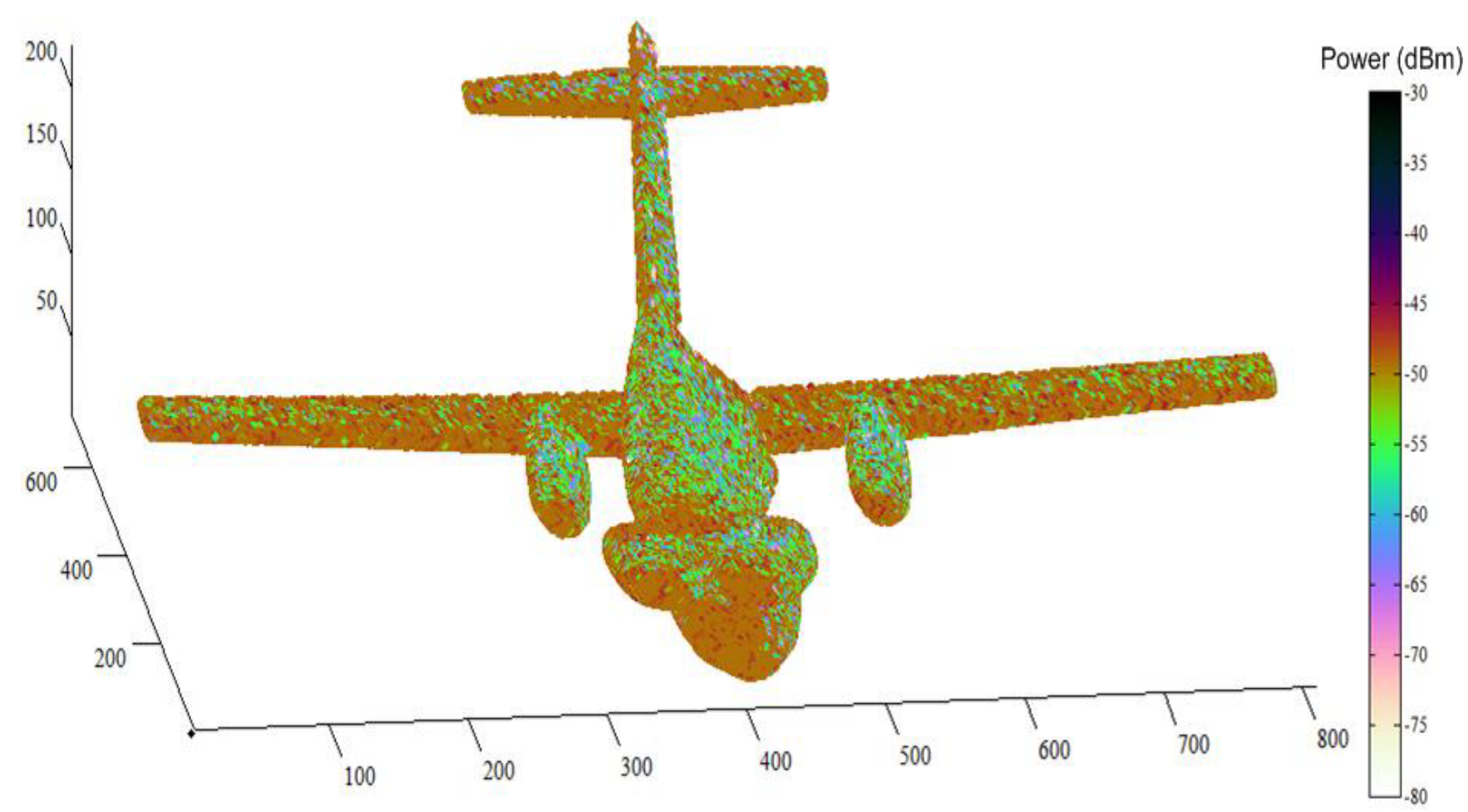

Figure 8: Simulation results for the EMI field incident on the Evektor EV-55 business jet from Ka-band antenna.

The results depicted, imminently define that at cruising altitude, the undercarriage of the aircraft is illuminated by a mean power of $-49.35 \mathrm{dBm}$. This implies that an EM field power density of $0.029 \mathrm{~mW} / \mathrm{m}^{2}$ is incident on the fuselage surface.

The accuracy of the developed ray-tracing model is however also able to further enhance the result attained from direct line-of-sight illumination. This is achieved by making use of the inherent characteristics of ray tracing which provide the ability to take into consideration particular locations on the external aircraft fuselage that are subject to different levels of EMI due to the holistic computation of all reflections that occur on the fuselage structure. This is evidenced in Figure 8 , by the variation in the EM field intensity levels incident on the regions where separate fuselage structures are adjacent together, such as the wing and rotor areas. The simulation illustrates that areas on the external structure that are subject to multipath generated EM fields which result in constructive or destructive summation of the high-frequency interference, with signals levels reaching peaks of $-44.57 \mathrm{dBm}$ and $-74.819 \mathrm{dBm}$ respectively.

\section{Conclusion}

This paper has presented the implementation of a ray tracing algorithm specifically designed to estimate the levels of EMI on the exterior fuselage of an aircraft due to the uplink transmission path of a $\mathrm{Ka}$ band satellite communication system. The algorithm performs a comprehensive consideration of the diverse propagation phenomena, together with complex analysis of the atmospheric parameters to generate a holistic calculation of the EM field that is resultant on the fuselage structure. The results obtained allow for an inclusive understanding of the incident EMI and provide an additional opportunity to assess the influence external communication systems impart on aircraft.

\section{ACKNOWLEDGMENT}

This work forms part of the project HIRF SE which is financially supported under the European Union 7th Framework Programme (FP7). The authors are solely responsible for the contents of the paper which does not represent the opinion of the European Commission 


\section{REFERENCES}

[1] A.R Sharul Kamal, C.S. Sum, A.R. Tharek, M. Zoinol Abidin and M.A. Awang, "Rain attenuation study over terrestrial and earth-satellite links in Malaysia", in Proc. of the 27th URSI General Assembly, Netherlands, Aug. 2002.

[2] A.D. Panagopoulos, P.D.M. Arapoglou, G.E. Chatzarakis, J.D. Kanellopoulos, and P.G. Cottis, "Unbalanced large scale multiple site diversity performance in satellite communication networks," in Proc. of the 28th URSI General Assembly, New Delhi, India, Oct. 2005.

[3] L.J. Ippolito, "Propagation effects handbook for satellite systems design", $4^{\text {th }}$ Edition, NASA.

[4] 2001 Federal Radionavigation Systems, DOT-VNTSCRSPA-0103.1/DOD-4650.5, U.S. Department of Defence and Transportation, Washington, DC, 2001.

[5] K.W. Hurst and S.W. Ellingson, "Path loss from a transmitter inside an aircraft cabin to an exterior fuselagemounted algorithm," in IEEE Trans. on Electromagnetic Compatibility, Vol. 50, No. 3, pp. 504-512, Aug. 2008.

[6] C. De Raffaele, C.J. Debono and A. Muscat, "Modeling Electromagnetic Interference Generated by a WLAN System Onboard Commercial Aircraft," in Proc. of the 15th IEEE Mediterranean Electrotechnical Conference (MELECON 2010), pp. 699-704, Malta, Apr. 2010.

[7] K. Chetcuti, C.J. Debono, R.A. Farrugia and S. Bruillot, "Wireless propagation modelling inside a buisness jet", in Proc. of Eurocon 2009, pp. 1640-1645, May 2009.

[8] N.R. Diaz and J.E. Esquitino, "Wideband channel characterization for wireless communications inside a short haul aircraft," in Proc. of the 59th IEEE Vehicular Technology Conf., pp. 223-228, Germany, May 2004.

[9] G.A. Berit, H. Hachem, J. Forrester, P. Guckian, K.P. Kirchoff and B.J. Donham "RF propagation characteristics of in-cabin CDMA mobile phone networks" in Proc. of the 24th Digital Avionics Systems Conf, Vol. 2, pp. 12, USA, Dec. 2005.

[10 ] N.R. Diaz and M. Holzbock, "Aircraft cabin propagation for multimedia communications," in 5th European Mobile and Personal Satellite Communications Workshop, Italy, September 2002.

[11] RTCA SC-202, "Guidance on allowing transmitting portable electronic devices (T-PEDs) on aircraft", RTCA, Inc., Washington, DC, DO-294B, Dec. 2006.

[12] RTCA SC-202, "Aircraft design and certification for portable electronic devices (PED) tolerance", RTCA, Inc., Washington, DC, DO-307, Oct. 2007.
[13] S.V. Georgakopoulos, C.R Birtcher, C.A. Balanis and R.A. Renaut, "HIRF penetration and PED coupling analysis for scaled fuselage models using a hybrid subgrid $\operatorname{FDTD}(2,2) / \operatorname{FDTD}(2,4)$ method," in IEEE Trans. on Electromagnetic Compatibility, Vol. 45, No. 2, pp. 293305, May 2003.

[14] B.E. Geschwendtner, G. Wolfle, B. Burk and F.M. Landstrofer, "Ray tracing vs. ray launching in 3-D microcell modeling" in Proc. of the European Personal and Mobile Communications Conf., pp 74-79, 1995.

[15] J. Lacik, Z. Lukes and Z. Raida, "On using raylaunching method for modeling rotational spectrometer," in Radioengineering, Vol.17, No.2, pp.98-107, June 2008.

[16] F.T. Ulaby, Electromagnetics for Engineers, Pearson International Edition, Prentice Hall, 2005.

[17] C.J. Debono and R.A. Farrugia, "Optimization of the UMTS network radio coverage on-board an aircraft," in Proc. of the IEEE Aerospace Conf., March 2008.

[18] K.W. Cheung and R.D. Murch, "Measurement, characterization and modeling of the wideband indoor channel," in Proc. of the 46th IEEE Vehicular Technology Conf., pp 588-592, Atlanta, April 1996.

[19] L. Boithias, Radio Wave Propagation, McGraw-Hill Inc., New York, 1987.

[20] C.M. Ho, C. Wang, K. Angkasa and K. Gritton, "Estimation of microwave power margin losses due to earth's atmosphere and weather in the frequency range of 3-30 GHz" in report for USA Air Force, California, Jan 2004.

[21] D.Didascalou, "Ray-optical wave propagation modelling in arbitrarily shaped tunnels", Ph.D. dissertation, Univ. of Karlsruhe, Germany, 2000.

[22] M. Born and E. Wolf, Principles of Optics, 7th Ed., Cambridge University Press, Cambridge, 1999.

[23] E. Lengyel, Mathematics for 3D Game Programming and Computer Graphics, 2nd Ed., Charles River Media, 2003

[24] C. De Raffaele, C.J. Debono and A. Muscat, "Small Aircraft Cockpit Electromagnetic Interference Due to UMTS Signal Propagation", in Proc. of IEEE Int. Conf. on Wireless Information Technology and Systems, Honolulu, Hawaii, Aug. 2010. 
[25] A.D. Panagopoulos, P.D.M. Arapoglou and P.G. Cottis, "Satellite communications at $\mathrm{Ku}, \mathrm{Ka}$, and $\mathrm{V}$ bands: Propagation impairments and mitigation techniques," in IEEE Communications Surveys and Tutorials, Third Quarter, Vol 6, No. 3, pp. 2-14, 2004.

[26] R.A. Farrugia and C.J. Debono, "Accurate modelling of Ka-band videoconferencing systems based on the quality of experience," in IET Communications, vol. 3, issue 1, pp. 67 - 74, January 2009..

[27] R.Crane, "Electromagnetic wave propagation through rain", Wiley-Interscience, 1996.

[28] ITU Recommendation ITU-R P.618-7, "Propagation data and prediction methods required for the design of Earth-space telecommunication systems", 2001.

[29] Y. Gataullin and R. Kozlowski, "Implementation of rain and gaseous attenuation models for $26-30 \mathrm{GHz} \mathrm{Ka}-\mathrm{Band}$ Communication" in Proc. of the 6th IASTED Int. Conf. Antennas, Radar, and Wave Propagation, pp. 54-61, Canada, Jul. 2009.

[30] D. Magdum, “Applications of propagation models to design geostationary satellite links operating in Ka-band over indian rain zones", in Proc. of the 28th URSI General Assembly, New Delhi, India, Oct. 2005.

[31] ITU Recommendation ITU-R P.618-7, "Propagation data and prediction methods required for the design of Earth-space telecommunication systems", 2001.

[32] ITU Recommendation ITU-R P.840-3, “Attenuation due to cloud and fog", 1999.

[33] ITU Recommendation ITU-R P.836-4, "Water vapour: surface density and total columnar content", 2009.

[34] M.J.L. Van de Kamp, C. Riva, J.K. Tervonen and E.T. Salonen, "Frequency Dependence of Amplitude Scintillation", in IEEE Trans. on Antennas and Propagation, vol. 47, pp. 77-85, January 1999.

[35] M.J.L. Van de Kamp, J.K. Tervonen, E.T. Salonen and J.P. Baptisita, "Improved models for long-term-prediction of tropospheric scintillation on slant paths", in IEEE Trans. on Antennas and Propagation, vol. 47, pp. 249260, February 1999.

[36] M.J.L. Van de Kamp, "Climatic radiowave propagation models for the design of satellite communication systems", Ph.D. dissertation, Eindhoven University of Technology, November 1999.

[37] Evektor Aviation EV-55 Web site:

http://www.evektor.cz/outback

\section{BIOGRAPHY}

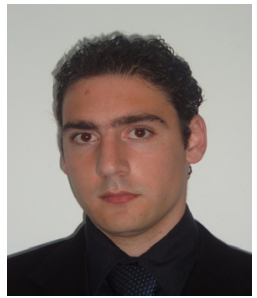

Clifford De Raffaele was conferred an electrical engineering first degree from the University of Malta on December 2008 and a masters degree in the department of Computer and Communications Engineering on November 2010.

During his studies he was employed in the embedded systems industry as a research and development engineer for two years. Subsequently, in 2009 he was employed on a European FP7 Research project regarding the EM interference on aircraft. His research interests include wireless communications, electromagnetic propagation, multimedia signal processing and embedded systems.

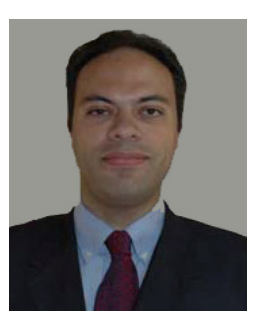

Carl James Debono received his B.Eng.(Hons.) degree in Electrical Engineering from the University of Malta, Malta, in 1997 and the Ph.D. degree in Electronics and Computer Engineering from the University of Pavia, Italy, in 2000.

Between 1997 and 2001 he was employed as a Research Engineer in the area of Integrated Circuit Design with the Department of Microelectronics at the University of Malta. In 2000 he was also engaged as a Research Associate with Texas A\&M University, Texas. In 2001 he was appointed Lecturer with the Department of Communications and Computer Engineering at the University of Malta and is now a Senior Lecturer. His research interests are in RF and microwave systems development and applications, and modeling of communication systems.

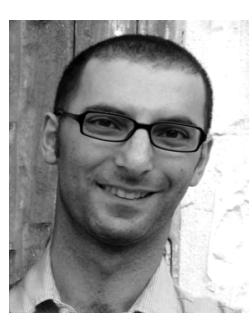

Adrian Muscat received his Bachelor's degree in Electrical Engineering from the University of Malta, 1993, the Masters degree from the University of Bradford, 1996, and the PhD from Queen Mary University of London, 2002.

After a short spell in industry he joined the Department of Communications and Computer engineering as a faculty member and today holds the position of Senior Lecturer. During the period 2008-2009 he spent a sabbatical year as a visiting academic at the University of Melbourne, where he carried out research in modelling geometry based $R F$ design. His research interests are in computer modeling and simulation applied to various applications including design science, mobile radio systems, Telematics, and virtual reality. 